\title{
OCHEM - on-line CHEmical database \& modeling environment
}

\author{
Sergii Novotarskyi ${ }^{1 *}$, lurii Sushko ${ }^{1}$, R Körner ${ }^{1}$, Anil Pandey Kumar ${ }^{1}$, Matthias Rupp ${ }^{1}$, W Prokopenko², Igor Tetko ${ }^{1}$ \\ From 5th German Conference on Cheminformatics: 23. CIC-Workshop \\ Goslar, Germany. 8-10 November 2009
}

The main goal of OCHEM database http://qspr.eu is to collect, store and manipulate chemical data with the purpose of their use for model development. Its main features, that distinguish it from other available databases include:

1. The database is open and it is based on Wiki-style principles. We encourage users to submit data and to correct inaccurate submitted data;

2. The database is aimed at collecting high-quality data. To achieve this we require users to submit references to the article, where the data was published. The reference may include the article name, journal name, date of publication, page number, line number, etc.

3 . Since the compound properties may vary depending on the conditions, under which they were measured, we store the measurement conditions with the data to provide the users with more accurate information about each data point.

The modeling framework is being developed to complement the Wiki-style database of chemical structures. Its main goal is to provide a flexible and expandable calculation environment that would allow a user to create and manipulate QSAR and QSPR models on-line. The modeling framework is integrated with the database web-interface that allows easy transfer of database data to the models. The web interface of the modeling environment is aimed to provide to the Web users easy means to create high-quality prediction models and estimate their accuracy of prediction and applicability domain. The developed models can be published on the Web and be accessed by other users to predict new molecules on-line. This tool is aimed to generate a new paradigm for structure activity relationship knowledge bases, making QSAR/QSPR models active,

${ }^{1}$ Institute of Bioinformatics and Systems Biology - Helmholtz Zentrum Muenchen, German Research Center for Environmental Health, Ingolstaedter Landstrasse 1, D-85764 Neuherberg, Germany user-contributed and easily accessible for benchmarking, general use and educational purposes. The examples of the use of the database within national and EU projects will be exemplified.

\section{Author details}

'Institute of Bioinformatics and Systems Biology - Helmholtz Zentrum Muenchen, German Research Center for Environmental Health, Ingolstaedter Landstrasse 1, D-85764 Neuherberg, Germany. ${ }^{2}$ Kiev, Ukraine.

Published: 4 May 2010

doi:10.1186/1758-2946-2-S1-P5

Cite this article as: Novotarskyi et al:: OCHEM - on-line CHEmical database \& modeling environment. Journal of Cheminformatics 2010 2(Suppl 1):P5.

\footnotetext{
Publish with ChemistryCentral and every scientist can read your work free of charge

"Open access provides opportunities to our colleagues in other parts of the globe, by allowing anyone to view the content free of charge." W. Jeffery Hurst, The Hershey Company.

- available free of charge to the entire scientific community

- peer reviewed and published immediately upon acceptance

- cited in PubMed and archived on PubMed Central

- yours - you keep the copyright

Submit your manuscript here:

http://www.chemistrycentral.com/manuscript/

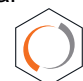
Chemistry Central
} 